It is certainly a remarkable object, as on a comparison with the list of meteorites recorded in Great Britain, published in the British Museum Guide to Meteorites, there is only one given of greater weight, that fell at Wold Cottage in Yorkshire in $\mathbf{1 7 9 5}$.

The outer coating, which varies from a very thin film to nearly $2 \mathrm{~mm}$. in thickness, presents a very finely-pitted surface, with evidence of a tendency to show lines of movement, as though the heated skin was being pushed backwards from the direction of motion. The portions which had become fused showed a dark glazed or shiny surface, this evidently being the forward end, and the portion to which the heat from the compressed air in front of it was most effective. The appearance of the pittings suggest that the heating of the surface was the means of liberating some portions of the structure of the mass, and that these would provide what is seen as the trail of the meteor after it has passed in its flight through the air, being the continued glow of the heated emissions by combination with the oxygen in the air.

There is evidence that some portions of the surface

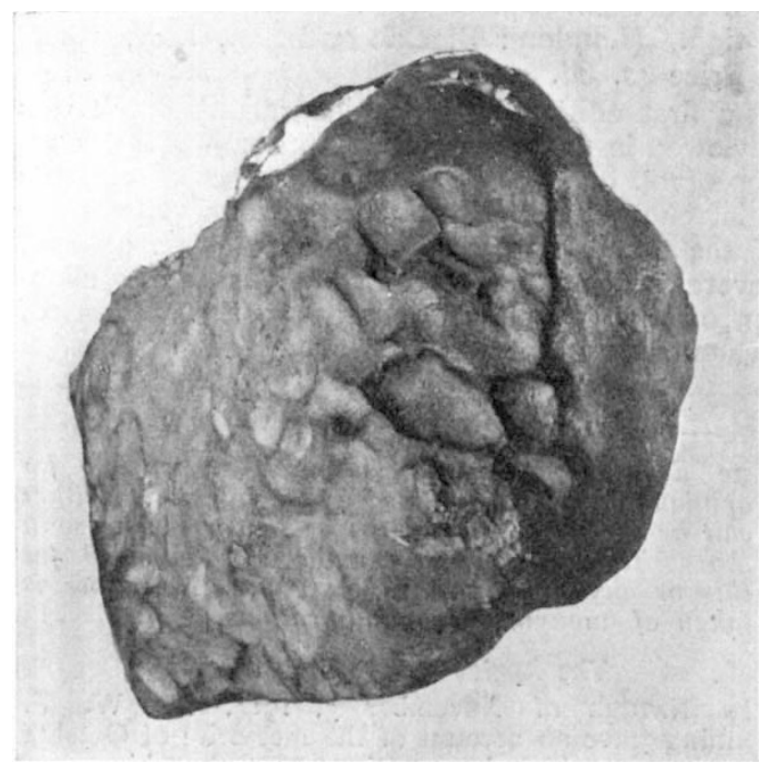

Appley Bridge Aerolite, October $1_{3}, 1_{9} 4_{40}$

had only come into contact with the air during the later portion of its traverse. These regions have all the appearance of flakes of the outer skin having been broken away, a slight tarnishing of the pyrites, if at a distance from the edge of the fracture or slight fusing when close to the general outer coating, indicating a removal of portions of outer layers of the mass.

This is quite in keeping with the assumption that the fragments were split off at the time of the apparent burst in the air, at about twenty miles' altitude, as from that position the speed of the meteor would be so much reduced by the compressional friction, that it would be losing more heat than gaining.

The fractured surface on an inspection appeared to be made up of a glittering mass of white and yellow points in a grey setting. These proved to be chiefly pyrites, and their presence accounted for the apparent great weight according to the size. The specific gravity of the mass determined from a fragment was 3.33 , and is in accord with what would be NO. 2358 , VOL. 94] expected from the mineralogical contents. A magnetic examination of the mass as a whole gave no appreciable effect, although a search amongst the dust which accumulated from the rubbing of the two pieces, indicated portions of magnetic nature though small in amount which proved to be metallic iron.

The pyritic material contains nickel as well as iron, portions being crystalline, the olivine being of a pale yellowish-green colour, whilst the enstatite is whitish or grey.

The proportions of the minerals worked out on the basis of the composition and solubility are approximately :-

$\begin{array}{lcccccc}\text { Pyritic and } & \text { metallic } & \text { matter } & \ldots & \ldots & 5 \cdot 07 \\ \text { Enstatite } & \ldots & \ldots & \ldots & \ldots & \ldots & 31.5 \\ \text { Olivine } & \ldots & \ldots & \ldots & \ldots & \ldots & 63.43\end{array}$

The analysis which has been made by Mr. E. L. Rhead indicate the presence of the following in order of amount:-

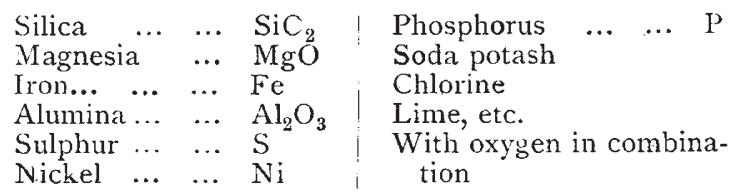

The accompanying illustration shows the front view of the aerolite with the thumb marks.

William C. Jenkins.

I I Upper Lloyd Street, Moss Side, Manchester, December 27, 1914.

\section{A Suggested Definition of Magnetic "Permanence."}

From time to time accounts appear of experiments on new kinds of steel which have been undertaken with the object of determining the most suitable material from which to construct a permanent magnet. Experiments of my own on this subject, made a good many years ago, led me to think that it would be an advantage if precision could be given to the term "permanence" in magnetism, and inasmuch as a high coercive force is the principal factor in the preservation of the magnetism in a magnet the measure of permanence, I think, might be taken as the coercive force per unit of residual magnetic intensity. Thus the inclination of the intensity-field curve as it falls from residual to zero intensity indicates what the permanence of the magnet may be expected to be.

According to this definition the permanence of soft iron is about 0.0024 . Recent experiments by Miss Margaret Moir (Phil. Mag., November, 1914) on chrome steel give the high permanence of $0 \cdot 165$, or, if the calculation is made from final residual magnetism after shocks and changes of temperature, of $0 \cdot 20 r$. These examples show a range of permanence from 0.0024 to 0.201 , in the ratio of $I$ to 84 , but it is not unlikely that these limits may be exceeded.

55 King Street South, Rochdale.

J. R. AshwORTH.

\section{EUROPEAN AERODYNAMICAL LABORATORIES. ${ }^{1}$}

$\mathrm{I}^{\mathrm{N}}$ the summer of $19 \mathrm{I}_{3}$ Prof. Zahm and Lieutenant Hunsaker, of the United States, visited the Furopean aerodynamical laboratories in order to study apparatus and methods in use, before finally deciding on the details of the material to be

I Report on European Aeronautical Laboratories. By Dr. A. F. Zahm. Smithsonian Miscellaneous Collections, vol. lxii., No. 3. (Washington: Smithsonian Institution, 1914.) 
provided by laboratories in America. Prof. Zahm is the Recorder of the Langley Laboratory of the Smithsonian Institution, whilst Lieut. Hunsaker is connected with the School of Technology, Boston. Report No. 2273 is a critical study by Prof. Zahm of European apparatus and methods, but the detailed application of the criticism is still unknown made for him by the Cambridge Scientific Instrument Co. It is probable that the installation is now in working order in the Massachusetts Institute of Technology.

In his report Prof. Zahm gives brief descriptions of the wind tunnels in Paris, Göttingen, and London, and some of the illustrations in the report

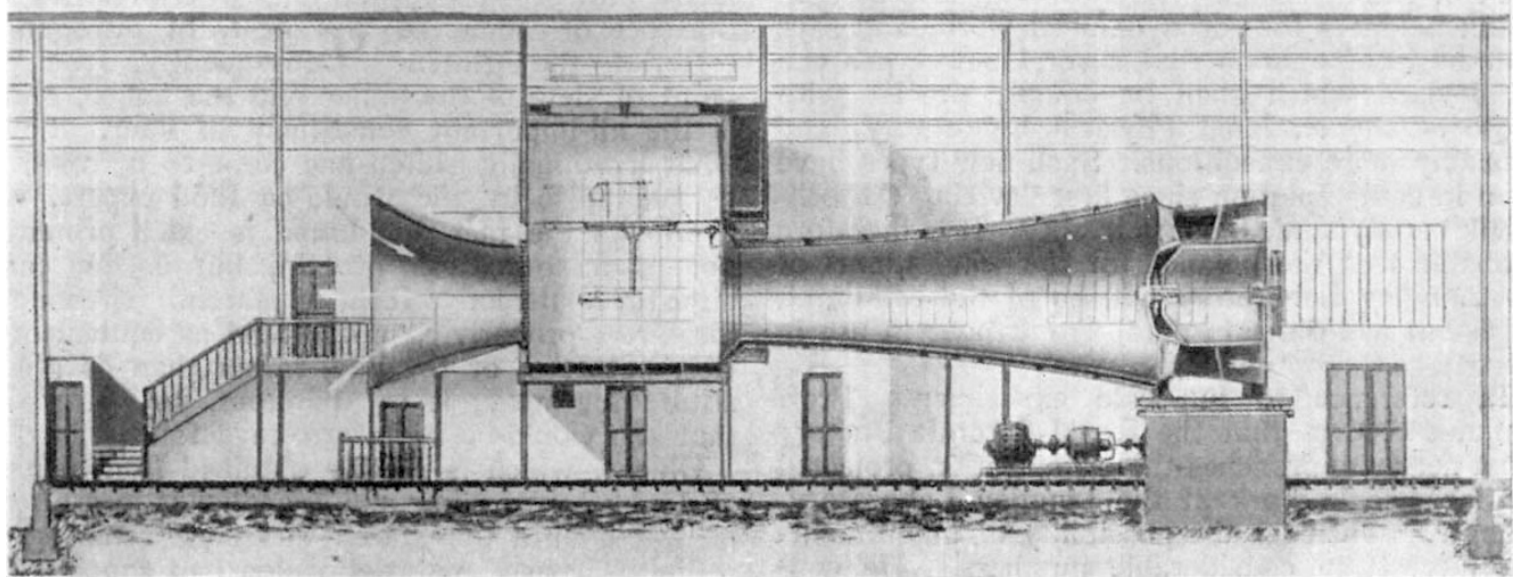

Fig. x.-Longitudinal section of the large wind tunnel, Eiffel Aerodynamical Laboratory.

as the re-opening of the Langley Laboratory cannot yet be said to be effective.

The present position appears to be that a scheme of work has been submitted to an advisory board which advocates the provision of a wind tunnel and of facilities for large-scale experiments, and it appears to be intended that the work of the Lang-

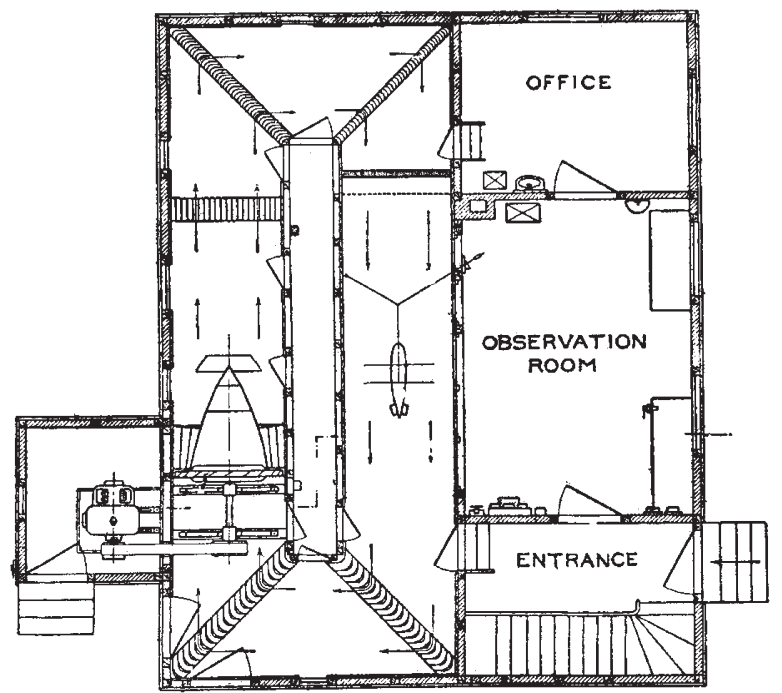

F1G. 2.-Göttingen Aerodynamical Laboratory.

ley Laboratory should be practically unimited in its scope.

Lieut. Hunsaker is not directly represented in this report, but it is known that immediately on his return to America he proceeded to erect a four-foot wind tunnel similar to that at the National Physical Laboratory, the aerodynamic balance being NO. 2358, VOL. 94$]$ are reproduced in Figs. I, 2, and 3. In M. Eiffel's apparatus the air current traverses the centre of a large room, and one of its advantages is the facility with which models can be moved into and out of the air current. It is further claimed by M. Eiffel that the absence of walls is an advantage in removing some constraint usual in wind tunnels.

In the Göttingen installation, Figs. 2 and 3 , air

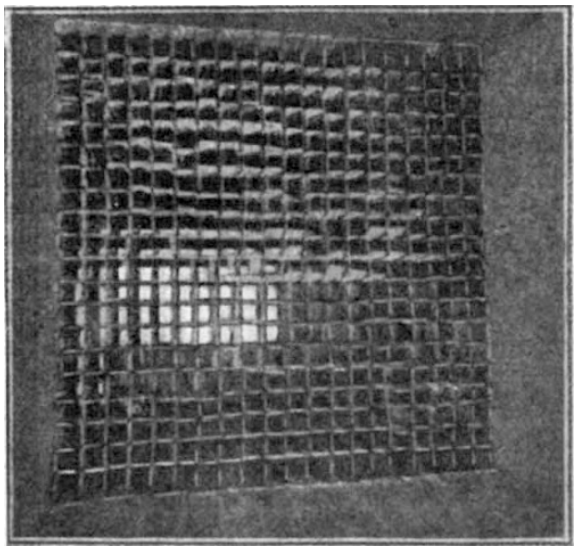

FIG. 3.-Prandtl's honeycomb in wind-tunnel.

is circulated horizontally through a tunnel containing four right-angle bends, and numerous guideblades are necessary in order to produce a good distribution of velocity in the working section. Fig. 3 gives some indication of the amount of labour involved in the production of a satisfactory result, and for this reason the writer was informed by Prof. Prandtl that the design would not be followed in a new wind tunnel under consideration. 
The wind channels at the National Physical Laboratory were recently described in NATURE, and little need be reproduced of Prof. Zahm's report. He describes the aerodynamic current as the steadiest in the world with limits of $\frac{1}{2}$ per cent. in both time and space. The steadiness of the air-flow in the Eiffel apparatus is stated to be 2 per cent. in time and space.

Prof. Zahm claims priority for the use of bellcrank balances for aerodynamical work, and says that he is of opinion that several new types can be devised which shall be equally precise with those at the National Physical Laboratory, and probably more expeditious. Such new types have been in contemplation since first devising the bellcrank aerodynamic balance in 1902 . It is therefore probable that the balance for the wind tunnel of the Langley Laboratory will be of the bell-crank type, but will differ in detail from those in use in Europe at the present time.

In reference to full-scale experiments, Prof. Zahm considers that the Royal Aircraft Factory most nearly approaches the organisation projected for large-scale work at the Langley Laboratory, though he excludes the possibility of manufacturing aircraft in considerable numbers. He considers the outcome of the large-scale experiments at the Royal Aircraft Factory to be the production of a stable, efficient, and safe biplane. Reports from the seat of war add strong support to this view.

A considerable amount of space in the report is devoted to a description of the apparatus for largescale experiments at St: Cyr, near Paris, and the remark is made that the relative importance of such large-scale tests as can be carried out on moving carriages, as compared with model tests or full-scale flights with instruments mounted on the aeroplane, has yet to be determined. The diffculties of experiment are indicated by the statement that the lift measurements on simple lifting surfaces are 5 per cent. in error, whilst the resistance measurements are much less accurate.

It is interesting to note that at the time of the visit, no aerodynamical experiments had been made in Germany other than those at Göttingen, but that arrangements were almost completed for large-scale work at Adlershof, near Berlin. For further particulars reference should be made to the original report.

\section{CHEMISTRY OF WHEAT AND FLOUR.}

GEWER than ten years ago most millers and bakers would have scoffed at the idea of there being any connection between chemistry and wheat or flour, and even the man of science would have admitted that the application of chemistry to such problems as the cereals presented was in its earliest infancy. Progress, however, has come rapidly and not only is the actual knowledge in the field now very considerable, but it has been already of the utmost value when applied in practice, so that scientific milling as well as scientific baking have made great strides.

NO. 2358 , VOL. 94]
It is safe to forecast that chemistry is destined to play as important a part in the manufacture of Hour in the future as mechanical science has done in the past, and it is satisfactory to note that there is every indication that Britain is more than prepared to hold her own in this development.

Flour is primarily a starchy material, but those characteristic properties which enable it to be made into bread are due almost entirely to the presence of some ro per cent. of nitrogenous material-the gluten. Consequently, from the point of view of the miller and the baker, gluten is the all-important constituent of flour. Somewhat irrationally gluten has come to be regarded as such also by the would-be food expert, who overlooks the fact that bread is eaten primarily, not as a source of protein, but as an easily digestible, attractive form of starch. The man in the street properly regards bread as equivalent to rice, potatoes, or the like, rather than as a substitute for meat; it is, therefore, not surprising that the would-be agitators have failed.

Gluten, which is readily obtained from a piece of dough by washing and kneading it in a stream of water until the starch has been removed, is a light brown material which has considerable elasticity.

From the chemical aspect, gluten is a mixture of several proteins, of which two only are of importance so far as its bread-making properties are concerned. These are named gliadin and glutenin, and they are apparently chemical entities so far as this description can be applied to any protein. Gluten is characterised by the properties of ductility and tenacity so that in dough it can entangle air in its cavities, which swell during fermentation and still more when heat is applied.

Wheat grown in different parts of the world is far from being always the same nor does the flour derived from it give the same type of bread. It has long been known that certain types of flour give a large, well-aerated loaf, generally white in colour, and very palatable, whereas other types give a small loaf which is close in texture, dull in colour, and of a stodgy character. Such flours are distinguished as strong and weak and are valued with a difference of several shillings a sack in their price. It has been attempted to express this difference between strong and weak wheats by analysis, and from time to time strength has been correlated with high nitrogen content or, what amounts to the same, a high percentage of gluten, or again to a certain ratio of glutenin to gliadin. Though there is a rough parallelism between strength and these factors, it is in no case absolute, so that no one of them could be said to be the cause of strength. Indeed, the solution of the question has been found in quite another direction.

Gluten prepared from the strongest flour, when carefully cleaned by repeated washing in distilled water, loses its properties; it has neither ductility nor tenacity and partly dissolves in the water. 